\title{
Pattern of illnesses before cot deaths
}

\author{
A N STANTON AND J R OAKLEY \\ Scarborough General Hospital, and Sutton Coldfield
}

SUMMARY The reasons for referral to hospital of 147 babies subsequently included in the DHSS study of postneonatal infant mortality were analysed and compared with those of 104 control infants. Although similar numbers were seen as outpatients, $71(16 \%)$ of the babies who died unexpectedly, but only 28 controls had previously been admitted to hospital. The excess was explained by acute infections, loss of consciousness, possible child abuse, and failure to thrive for non-organic reasons. The average length of admission was almost twice that required by controls, and $31 \%$ were admitted more than once. The admissions were often clues to important family problems that might have been investigated further. There were no admissions for unexplained apnoea and 'near miss' cot deaths may not therefore represent a suitable model for the investigation of most unexpected deaths during infancy.

Most postneonatal infant deaths occur unexpectedly. Only a minority of these babies have symptoms of a terminal illness severe enough to suggest that their parents should have sought medical help, ${ }^{1}$ and therefore there is an urgent need for earlier identification of babies at increased risk of unexpected death. Attempts have been made to identify such babies in the early neonatal period, but with only limited or local success. ${ }^{23}$ An alternative approach is to analyse the problems that necessitate outpatient follow up after discharge from the maternity hospital or referral for specialist paediatric assessment by family doctors. Reports from Northern Ireland ${ }^{4}$ and Oxford $^{5}$ suggest that an important minority of babies who die unexpectedly at home have previously been admitted to hospital. Furthermore, the Sheffield multistage system for identifying babies at risk of cot death uses admission to hospital, up to the age of 21 weeks, as a factor that elevates babies from intermediate to high risk, without specifying the cause of admission. ${ }^{2}$

This controlled study analyses the inpatient and outpatient hospital contacts of babies who subsequently died unexpectedly and were included in the DHSS study of postneonatal infant mortality. It also seeks to explore the relation between cot deaths and their 'near miss' equivalents, because the latter are being used increasingly as the experimental model for understanding the physiological events that may cause sudden unexpected death. ${ }^{6}$

\section{Methods}

The DHSS study began in April 1976, based on
Sheffield, Newcastle upon Tyne, and Oxfordshire. By its conclusion in March 1979 the study had expanded to include Birmingham, Edinburgh, Fife and the Lothians, Gateshead, Leeds, Liverpool, Manchester, and South Yorkshire, with an overall population of eight million. A preliminary report has been published. ${ }^{1}$ All deaths of children aged between 1 week and 2 years occurring in these administrative areas were notified to the study. Whenever possible deaths of babies who had been discharged from their maternity hospital were investigated, including standardised interviews with the parents, family doctor, and health visitor and an abstraction of all medical records. A conference about each death was held, at which all those working with the family, together with the interviewer and a paediatrician, discussed the clinical findings.

A control child was identified from a local chronological list of birth notifications by counting a predetermined number of names below that of the child who died, so that ages were matched to within 2 days. In Oxfordshire, two controls were found for each case. The same detailed interviews were sought from parents, family doctors, and health visitors, and medical records were abstracted up to the date of death of the index baby.

Babies who died unexpectedly were eligible for inclusion in the present study if the conference concluded that their death was not explained by life threatening congenital defects, the complications of prematurity, neoplasia, or violence. Information was analysed to identify those who had had hospital 
Table 1 Previous hospital contacts of 467 babies who subsequently died unexpectedly and 511 controls*

\begin{tabular}{lcc}
\hline & $\begin{array}{c}\text { Babies } \\
\text { died }\end{array}$ & Controls \\
\hline Any previous hospital attendance & 147 & 104 \\
Inpatient & 71 & 28 \\
Outpatient & 76 & 76 \\
No hospital contact & 306 & 386 \\
No information available & 14 & 21 \\
\hline
\end{tabular}

* Each of $\mathbf{4 4}$ Oxfordshire cases had two controls.

Table 2 Age at first admission to hospital of 71 babies who subsequently died unexpectedly and 28 controls

\begin{tabular}{llc}
\hline & $\begin{array}{l}\text { Babies } \\
\text { died }\end{array}$ & Controls \\
\hline Less than 1 month & 12 & 5 \\
1 month & 22 & 10 \\
2 months & 11 & 4 \\
3 months & 10 & 3 \\
4-5 months & 5 & 2 \\
6-8 months & 8 & 1 \\
9-11 months & 1 & 1 \\
12-23 months & 1 & 2 \\
Not known & 1 & - \\
\hline
\end{tabular}

inpatient or outpatient management after discharge from the maternity hospital, excluding transfers to another hospital for specialist investigations and terminal admissions.

\section{Results}

Nine hundred and eighty eight deaths were notified. Of these, 467 were eligible for inclusion in the present study together with 511 controls (44 cases from Oxfordshire each had two controls). The availability of information about cases and controls and details of inpatient and outpatient attendance at a hospital are given in Table 1 . There was a marked excess of admissions to hospital among babies who subsequently died, compared with controls, and the excess was distributed throughout the study areas. All areas had similar numbers of cases and controls seen as outpatients, and there were no appreciable differences in the reasons these babies were followed up from the maternity hospital or referred by their family doctor.

Inpatient management. The age at first admission of the 71 babies who subsequently died and the 28 controls is given in Table 2. Almost half of those who subsequently died were admitted before 2 months of age and over three quarters before four months. A similar age distribution was seen in the controls.

The number of admissions to hospital of cases and controls is given in Table 3 . Twenty two (31\%) of
Table 3 Number of previous admissions to hospital of babies who subsequently died unexpectedly and their controls.

\begin{tabular}{lcl}
\hline No of admissions & Babies who died & Controls \\
\hline 1 & 49 & 25 \\
2 & 14 & - \\
3 & 5 & 2 \\
4 & 2 & - \\
5 & 1 & - \\
6 & - & 1 \\
7 & - & 28 \\
\hline Total: babies & 71 & 38 \\
Total: admissions & 105 & \\
\hline
\end{tabular}

Table 4 Principal causes of previous admissions to hospital of babies who died unexpectedly and controls

\begin{tabular}{|c|c|c|c|c|}
\hline & \multicolumn{2}{|c|}{ Babies who died } & \multicolumn{2}{|c|}{ Controls } \\
\hline & Cause & $\begin{array}{l}\text { Repeat } \\
\text { admissions } \\
\text { for same } \\
\text { cause }\end{array}$ & Cause & $\begin{array}{l}\text { Repeat } \\
\text { admissions } \\
\text { for same } \\
\text { cause }\end{array}$ \\
\hline Strong suspicion of child abuse & 8 & - & 一 & 一 \\
\hline Failure to thrive & 24 & (4) & - & 一 \\
\hline Feeding problems & 10 & (3) & 7 & (2) \\
\hline Gastroenteritis & 16 & - & 3 & 一 \\
\hline Respiratory tract infection & 18 & (2) & 4 & 一 \\
\hline Other infections & 4 & 一 & 1 & - \\
\hline Loss of consciousness & 12 & (3) & 1 & - \\
\hline Supraventricular tachycardia & 一 & - & 3 & (1) \\
\hline Pyloric stenosis & 5 & - & 3 & - \\
\hline Other surgery & 4 & - & 10 & (6) \\
\hline Miscellaneous & 4 & 一 & 6 & - \\
\hline Total admissions & 105 & & 38 & \\
\hline
\end{tabular}

the babies who subsequently died had been admitted to hospital more than once, but only three $(11 \%)$ of the controls. The average length of each admission was 11.7 days for babies who subsequently died (median duration 9 days) and 6.2 days for the controls (median duration 4 days).

The main diagnosis for each admission to hospital is given in Table 4. Readmissions (sometimes multiple) with the same diagnosis are noted in parenthesis: readmissions with different diagnoses are listed under the appropriate cause of admission. One control had 7 admissions for dilatations after neonatal repair of an oesophageal atresia and tracheo-oesophageal fistula. Babies who subsequently died had an excess of admissions for four main reasons-acute infections (36 cases: 8 controls); loss of consciousness (9: 1$)$; possible child abuse (8: 0$)$; and failure to thrive (22: 0 ). Virtually all the cases in which babies were investigated for failure to thrive were thought to be associated with social problems rather than caused by organic disorders. No episode of loss of consciousness was unexplained: almost all were associated with acute febrile illnesses.

The interval between discharge from hospital and 
Table 5 Interval between hospital discharge and death of 71 babies who died unexpectedly

\begin{tabular}{lr}
\hline Interval & No \\
\hline 1-6 days & 4 \\
$7-13$ days & 5 \\
14-30 days & 17 \\
1 month & 18 \\
2 months & 6 \\
$3+$ months & 21 \\
\hline
\end{tabular}

death is given in Table 5 . Only four babies $(6 \%)$ died within a week, and 9 babies (13\%) within a fortnight of discharge from hospital.

Attempts to follow up babies after discharge from hospital resulted in $28 \%$ of patients failing to keep at least one appointment arranged for a date before death. A similar proportion was found among the controls.

\section{Discussion}

This study suggests that admission to hospital may be an important event for some babies who subsequently die unexpectedly. Although only $16 \%$ gave this history, their admission rate was well in excess of that of the control population. They remained in hospital for twice as long and were far more likely to be readmitted on a subsequent occasion. Infection was the commonest diagnosis precipitating admission, but the illnesses were rarely life threatening. Minor symptoms which would not normally have warranted admission were also the reason for referral of most of the cases which the hospitals were to diagnose as failure to thrive for social reasons. The complexity of the family situations seems to explain the longer duration of the admissions, because an inability of parents to cope is often as important a factor in paediatric referrals as the severity of the illness itself. ${ }^{7}$ This was certainly evident in the small number of babies who died unexpectedly in whom there had been a strong suspicion of child abuse. Therefore the major importance of many of the admissions may have been that they were clues to considerable family problems that required further investigation and close liaison with the primary care and social work services. It remains unclear how recognition of the problems may be turned to practical use in preventing later unexpected death. In part, it involves helping the parents to appreciate the signs of illness which infants commonly exhibit. ${ }^{18}$ It also requires advice about not allowing a child to become too hot, especially with subsequent infection, ${ }^{9}$ because a recent large study has shown that $82 \%$ of babies have a raised temperature even after death is discovered. ${ }^{10}$ In $21 \%$ of babies reported in another study, the rise was above $40^{\circ} \mathrm{C} .11$

There are other possible explanations for the importance of these hospital admissions. Ill children could have been discharged too soon or may have become cross infected before discharge. Only $13 \%$, however, died within two weeks of leaving hospital. The babies may have had a predisposition to infection, but this was not reflected in the severity of the illnesses at admission, and was not the conclusion of the local case conferences. A more relevant consequence of the admissions may have been a disturbance of the bonding mechanisms within the family, because of the frequently prolonged separation of the baby from its parents.

The most striking observation of this study was that no baby had previously been admitted to hospital for an episode of unexplained apnoea. Although the absence of so called 'near miss' cot deaths accords with the findings of previous studies, ${ }^{412}$ recent research has concentrated on these cases to provide an understanding of the physiological mechanisms responsible for unexpected deaths during infancy. ${ }^{6}$ There may be a major flaw in the hypothesis that 'near misses' represent a model for the investigation of most cases of the sudden infant death syndrome, if the babies would not be expected to die. Hardly any babies were being issued with apnoea alarms at the time of this study, and so it is no explanation for the absence of such cases that they were already being prevented. Therefore studies which suggest an increased risk of cot death after investigated episodes of prolonged apnoea may over estimate the true danger. ${ }^{13}$ This is possibly because the number of centres investigating prolonged apnoea is so small that their facilities attract complicated cases not typical of those predominating in population studies of cot deaths. Other reports suggest that the danger of subsequent unexpected death is small, with or without home monitoring using apnoea alarms. ${ }^{14-16}$ Unfortunately there are no population studies of prolonged apnoea to provide any accurate comparison with the statistics of cot deaths, although attempts are being made to remedy the deficiency. ${ }^{17} 18$

The present study was not designed to investigate the physiological events preceding cot death, and it can do no more than suggest that the important factors triggering fatally prolonged apnoea still require elucidation. They are not restricted to the small number of babies who present to hospitals as 'near miss' cot deaths and comparisons with this group must be treated with caution. 
This work has been supported by grants from the DHSS. We are grateful to the families, doctors, health visitors, and interviewers for cooperating with the study; to Professor $J$ Knowelden and Dr $M$ Downham for advice; and to Mrs B Douglas and Mrs M Boulby for secretarial help.

\section{References}

1 Stanton AN, Downham MAPS, Oakley JR, Emery JL, Knowelden $\mathbf{J}$. Terminal symptoms in children dying suddenly and unexpectedly at home. $\mathrm{Br}$ Med $J$ 1978;ii: 1249-51.

2 Carpenter RG, Gardner A, McWeeny PM, Emery JL. Multistage scoring system for identifying infants at risk of unexpected death. Arch Dis Child 1977;52:606-12.

3 Oakley JR, Tavaré CJ, Stanton AN. Evaluation of the Sheffield system for identifying children at risk from unexpected death in infancy. Arch Dis Child 1978;53: 649-52.

4 Froggatt P, Lynas MA, Marshall TK. Sudden unexpected death in infants (Cot death). Report of a collaborative study in Northern Ireland. Ulster Med J 1971;40:116-35.

5 Fedrick J. Sudden unexpected death in infants in the Oxford Record Linkage Area. Details of pregnancy, delivery and abnormality in the infant. Br J Prev Soc Med 1974;28:164-71.

6 Shannon DC, Kelly DH. SIDS and near-SIDS. $N$ Engl LMed 1982;306:959-65,1022-8.

7 Stanton AN, McWeeny PM, Jay AL, Irwin E, Oakley JR. Management of acute illness in infants before admission to hospital. Br Med J 1980;280:897-9.

${ }^{8}$ Carpenter RG, Gardner A, Pursall E, McWeeny PM, Emery JL. Identification of some infants at immediate risk of dying unexpectedly and justifying intensive study. Lancet 1979 ;ii:343-6.
9 Downham MAPS, Stanton AN. Keep cool, baby: the risks of overheating in young babies. Health Visitor 1981; 54:325-8.

10 Pfeiffer K. Bedeutung der rektaltemperaturmessung und der umgebungsuntersuchungen beim plötzlichen kindestot. Dtsch Med Wochenschr 1980;105:1065.

11 Sunderland R, Emery JL. Febrile convulsions and cot death. Lancet 1981 ;ii:176-8.

12 Bergman AB, Ray CG, Pomeroy MA, Wahl PW, Beckwith JB. Studies of the sudden infant death syndrome in King County, Washington. III Epidemiology. Pediatrics $1972 ; 49: 860-70$.

13 Kelly DH, Shannon DC, O'Connell K. Care of infants with near-miss sudden infant death syndrome. Pediatrics $1978 ; 61: 511-4$.

14 Bergman AB, Beckwith JB, Ray CG. The apnea monitor business. Pediatrics 1975 ;56:1-3.

15 Hodgman JE, Hoppenbrouwers $\mathrm{T}$, Geidel $\mathrm{S}$, et al. Respiratory behavior in near-miss sudden infant death syndrome. Pediatrics $1982 ; 69: 785-92$.

16 Duffty P, Bryan MH. Home apnea monitoring in 'nearmiss' sudden infant death syndrome (SIDS) and in siblings of SIDS victims. Pediatrics 1982;70:69-74.

17 Kahn A, Blum D. Phenothiazines and sudden infant death syndrome. Pediatrics $1982 ; 70: 75-8$.

18 Jeffery HE, Rahilly P, Read DJC. Multiple causes of asphyxia in infants at high risk for sudden infant death. Arch Dis Child 1983 ;58:92-100.

Correspondence to Dr A N Stanton, Paediatric Department, Scarborough General Hospital, Scarborough, North Yorkshire.

Received 11 July 1983 